\title{
DETERMINING THE TECHNICAL STANDARDS OF PING PONG TABLE BY USING CLOSE RANGE PHOTOGRAMMETRY
}

\author{
U. Acar $^{\text {a }}$, B. Bayram ${ }^{\text {a }}$ H.I. Cetin ${ }^{\text {a }}$, F.B.Sanl ${ }^{\text {a }}$ \\ ${ }^{a}$ YTU, Civil Engineering Faculty, 34220 Esenler Istanbul, Turkey - (uacar, bayram, icetin)@yildiz.edu.tr
}

\section{WG V/1}

KEY WORDS: Metrology, Measurement, Rectification, Video, Non-Metric

\begin{abstract}
:
In the presented study, quality measurements were made regarding three different ping pong tables that were produced with three different materials. Measurements were made on the purpose of confirming whether the tables can be used as a match table that is in the standard of International Table Tennis Federation or not. For this confirmation, bouncing height of the table tennis ball is measured which is approved by ITTF. Average bouncing height that is required by federation standards is minimum $23 \mathrm{~cm}$ for free falling table tennis ball from $30 \mathrm{~cm}$.

In order to locate the bounce on the tables, the table tennis ball is released from $30 \mathrm{~cm}$ in free fall with equipment was. In the meantime, 24 video frames videos were shot with a Full HD (1920 x 1080) camera. Each frame of videos that were taken is separated from each other. Each frame is analyzed and highest bounce is measured.

As a result of the study, the bouncing heights of the three tables were measured as $23.04 \mathrm{~cm}, 23.33 \mathrm{~cm}, 22.91 \mathrm{~cm}$ for table1, for table 2 and for table 3 respectively.
\end{abstract}

\section{INTRODUCTION}

Table tennis is controlled by the worldwide organization International Table Tennis Federation (ITTF), founded in 1926. ITTF currently includes 215 member associations (http://www.ittf.com/_front_page/ittf2.asp?category=directory_ e. 25 May 2011) The table tennis official rules are specified in the ITTF handbook (http://www.ittf.com/ittf_handbook/ittf_hb.html. 16.04.2012) Since 1988, table tennis has been an Olympic sport, (http://www.nytimes.com/2008/04/05/business/05pursuits.html?_r=2, 5 April 2010)

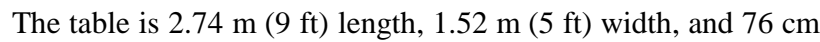
(30 inch) height with a Masonite (a type of hardboard) or similarly manufactured timber, layered with a smooth, lowfriction coating. (http://www.ittf.com/equipment/T1_Table\%202005.pdf. 28 July 2010). The table or playing surface is divided into two halves by a $15.25 \mathrm{~cm}$ (6 inch) high net. An ITTF approved table surface must be in a green or blue color.

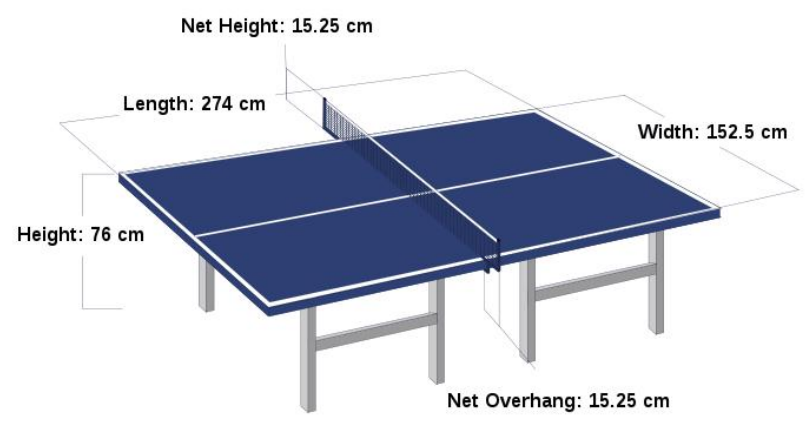

Figure 1. Table tennis table

(http://en.wikipedia.org/wiki/File:Table_Tennis_Table_Blue.sv g)

According to ITTF handbook, The Table Technical Leaflet T1, section 2.1.3 "The playing surface may be of any material and shall yield a uniform bounce of about $23 \mathrm{~cm}$ when a standard ball is dropped on to it from a height of $30 \mathrm{~cm}$."

Photogrammetry is the science of obtaining reliable and accurate measurements from photographs (W. T. C. Neale, 2004). Close range digital photogrammetry, has been applied successfully in a wide range of measurement applications for a significant period of time. The principles of such systems are well known (Fraser and Shortis, 1995) and they have common acceptance for industrial measurement applications (Ganci and Shortis, 1995a;b)

The implementation of digital photogrammetric measurement systems are increasing for the industrial applications (Schneider, 1996; Beyer et al., 1995; Brown and Dold, 1995; Pettersen, 1992). These systems has become more important not only with high measurement accuracy, but also with automation (Fraser, 1997), (Tan,2011).

This study, the table tennis tables which were made in Turkey, to control whether they fit ITTF standards with the close range photogrammetry. As a result, the bouncing height has been measured in $0.2 \mathrm{~mm}$-accuracy.

\section{METHODOLOGY}

In the study, according to the ITTF handbook, a mechanism has been prepared to drop the table tennis ball without spinning from the $30 \mathrm{~cm}$ - height. At the background of the mechanism, $5 \times 5$ sized grid measurement system was prepared. The grid has been placed to the table perpendicularly (figure 2 . figure 3 ). 


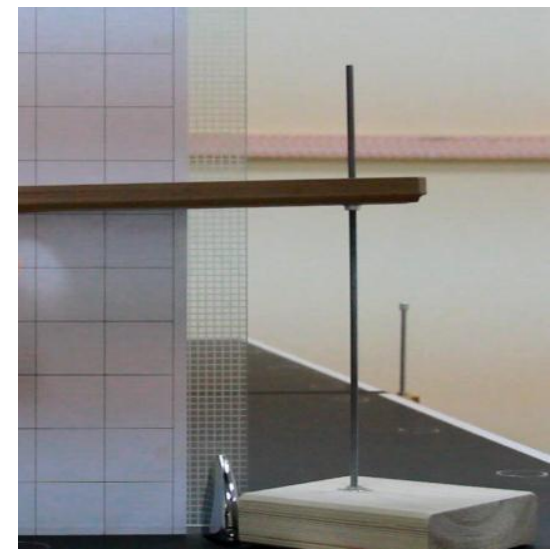

Figure 2. Ball dropping mechanism

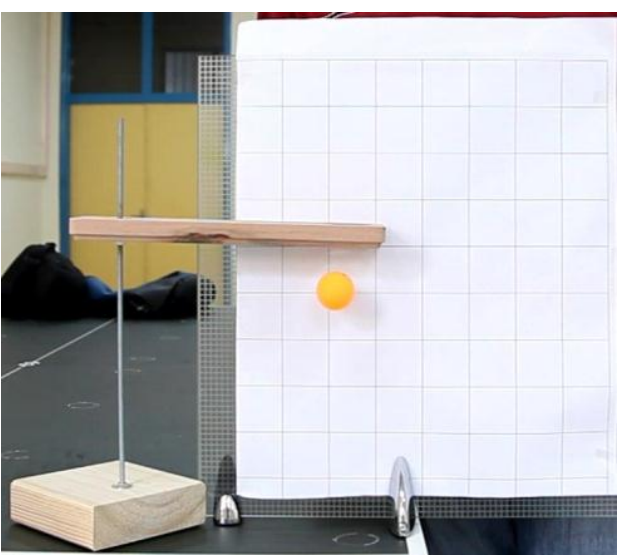

Figure 3. Control grid for measurement

To control the tables for the standards of the ITFF, the $40 \mathrm{~mm}-$ diameter table tennis ball which has been approved by ITTF (figure 4), has been dropped from $30 \mathrm{~cm}$-height to the 32 points on the table (figure 5). To determine the height of bouncing, a video capture has been taken.

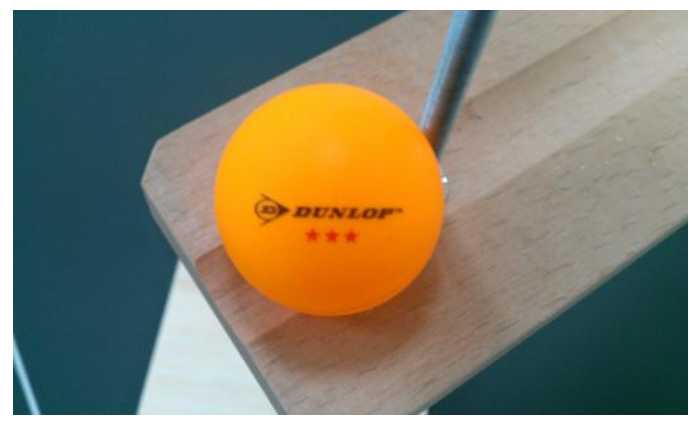

Figure 4. ITTF approved table tennis ball

For capturing the videos, Canon EOS 7D full HD camera has been used (figure 6). The pixel resolution of the camera is 18 megapixels with $22.3 \times 14.9 \mathrm{~mm}$ censor and the video camera resolution is $1920 \times 1080$ pixels (Full HD). The resolution of the camera is 18 micrometers. The video has been captured with 24 frames per second in the full HD mode. The diaphragm of the camera has been stabilized to 1:4:0 in all captures. The shutter has been selected $1 / 60$. Also the film has been captured with 400 ISO. During the capturing, Canon EF 24-105mm F/4 L IS USM type of lens has been used. The framing has been taken from the same height and distance. In order to prevent distortion of perspective, the camera tripod has not been chanced. The videos have been taken by zooming to the image. Thus, for each point, capture distance has been protected.

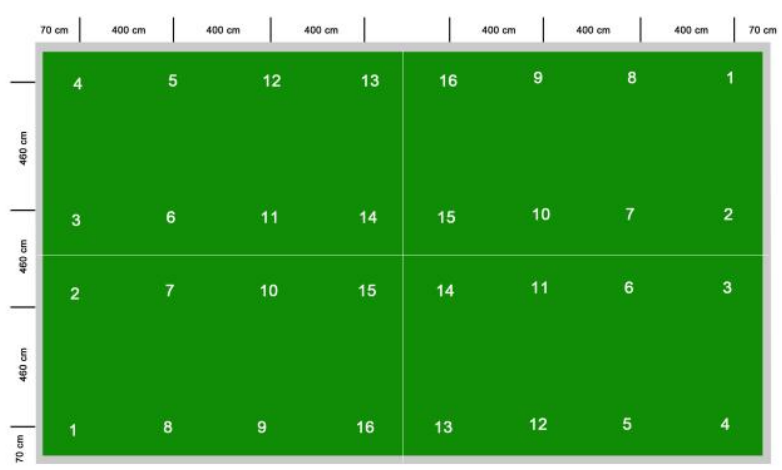

Figure 5. Measurement points in table

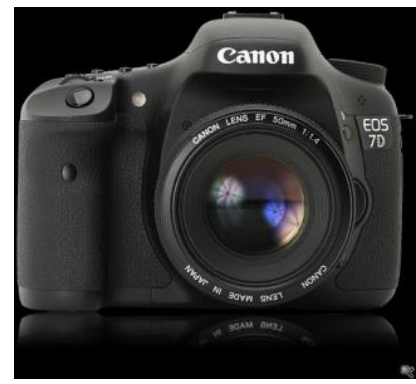

Figure 6. The Camera that was used

The frames that were obtained from the video have been evaluated separately in the CAD software. It is a graphical data editor, which is used for creation and modification of drawings, plans, etc. These systems have a large palette of PC graphic methods in a plane (2D) but also in (3D). (Samuhelová, 2004).

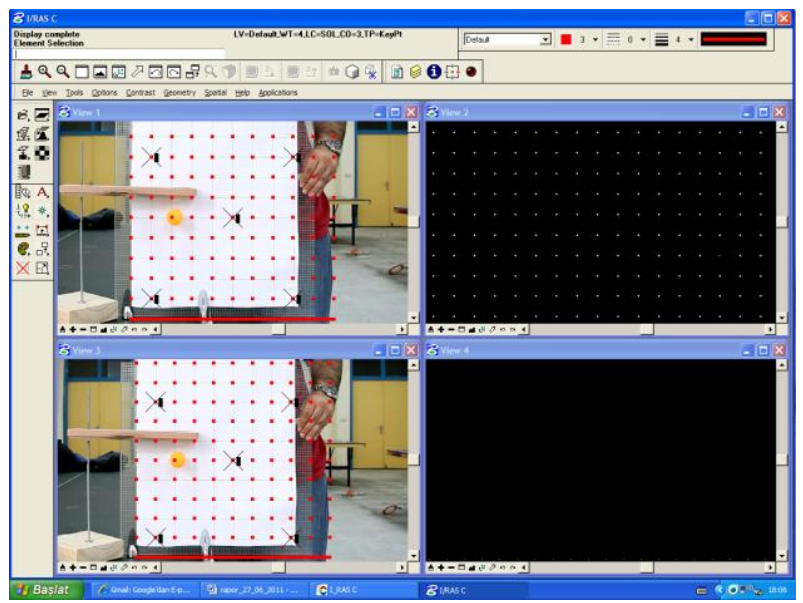

Figure 7. Scaling with projective transformation

To determine the bouncing height of the table tennis ball, the consecutive frames of the video has been used. In order to obtain better results, three measurements (shooting) have been taken at the each point of the table. In each capture, the first, second and third bounces of the table tennis ball have been recorded. For measurements projective transformation has been used with designed grid system. This procedure has been 
applied for 3 tables x 3 bounce $\mathrm{x} 32$ measurement points and all the images have been registered to the grid with projective transformation. The average error of the registration is $0.2 \mathrm{~mm}$ for three tables.

In figure 7 and figure 8 the measurement system has been depicted.

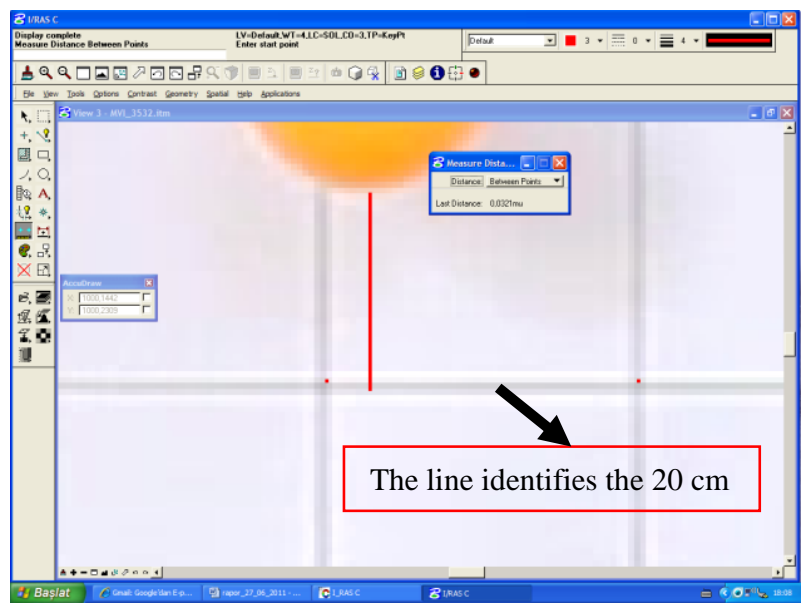

Figure 8. The distance measuring operation

\section{RESULTS}

In this study, three types of the ping - pong table were determined whether they fit the standards of ITFF or not by photogrammetric method.

The reason of working with two dimensions is to calculate the height of straight line which is tangent to the bottom of the ball. It has also same meaning as measurement of the bouncing height.

The average error of the projective transformation has been calculated $0.2 \mathrm{~mm}$ for three tables and the bouncing height has been measured in $0.1 \mathrm{~mm}$ precision.

The measurement results for three tables have been given in table 1 , table 2 and table 3 respectively.

\begin{tabular}{|c|c|c|c|}
\hline \multicolumn{4}{|c|}{ C Type 5 Table with Metal Legs. } \\
\hline & 1. Bounce & 2. Bounce & 3. Bounce \\
\hline Average $(\mathrm{cm})$ & 23.04 & 18.14 & 14.47 \\
\hline Minimum $(\mathrm{cm})$ & 21.65 & 16.43 & 12.35 \\
\hline Maximum $(\mathrm{cm})$ & 23.66 & 19.52 & 15.39 \\
\hline
\end{tabular}

Table 1. The average bouncing height for table1

\begin{tabular}{|l|l|l|l|}
\hline \multicolumn{4}{|c|}{ B Type 4 Table Wooden Legs. } \\
\hline & 1. Bounce & 2. Bounce & 3. Bounce \\
\hline Average $(\mathrm{cm})$ & 22.91 & 17.97 & 14.30 \\
\hline Minimum(cm) & 21.01 & 16.55 & 13.41 \\
\hline Maximum(cm) & 23.59 & 18.78 & 15.03 \\
\hline
\end{tabular}

Table 2. The average bouncing height for table2

\begin{tabular}{|l|l|l|l|}
\hline \multicolumn{4}{|c|}{ A Type 3 Pro Table } \\
\hline & 1. Bounce & 2. Bounce & 3. Bounce \\
\hline Average $(\mathrm{cm})$ & 23.33 & 18.56 & 15.1 \\
\hline Minimum $(\mathrm{cm})$ & 22.92 & 17.9 & 14.57 \\
\hline Maximum $(\mathrm{cm})$ & 23.74 & 19.23 & 15.79 \\
\hline
\end{tabular}

Table 3. The average bouncing height for table 3

For the $\mathrm{C}$ type 5 Table with metal legs, the maximum bouncing height has measured at the $17^{\text {th }}$ point as $23.66 \mathrm{~cm}$. and the minimum bouncing height has measured at $5^{\text {th }}$ point as 21.65 $\mathrm{cm}$ for first bouncing. The maximum bouncing height has measured at the $17^{\text {th }}$ point as $19.52 \mathrm{~cm}$. and the minimum bouncing height has measured at $22^{\text {th }}$ point as $16.43 \mathrm{~cm}$ for second bouncing. The maximum bouncing height has measured at the $18^{\text {th }}$ point as $15.39 \mathrm{~cm}$. and the minimum bouncing height has measured at $17^{\text {th }}$ point as $12.35 \mathrm{~cm}$ for third bouncing.

For the B type 4 Table with metal legs, the maximum bouncing height has measured at the $4^{\text {th }}$ point as $23.59 \mathrm{~cm}$. and the minimum bouncing height has measured at $30^{\text {th }}$ point as 21.01 $\mathrm{cm}$ for first bouncing. The maximum bouncing height has measured at the $4^{\text {th }}$ point as $18.78 \mathrm{~cm}$. and the minimum bouncing height has measured at $30^{\text {th }}$ point as $16.55 \mathrm{~cm}$ for second bouncing. The maximum bouncing height has measured at the $8^{\text {th }}$ point as $15.03 \mathrm{~cm}$. and the minimum bouncing height has measured at $20^{\text {th }}$ point as $13.41 \mathrm{~cm}$ for third bouncing.

For the A type 4 Pro Table, the maximum bouncing height has measured at the $8^{\text {th }}$ point as $23.74 \mathrm{~cm}$. and the minimum bouncing height has measured at $11^{\text {th }}$ point as $22.92 \mathrm{~cm}$ for first bouncing. The maximum bouncing height has measured at the $8^{\text {th }}$ point as $19.23 \mathrm{~cm}$. and the minimum bouncing height has measured at $11^{\text {th }}$ point as $17.90 \mathrm{~cm}$ for second bouncing. The maximum bouncing height has measured at the $32^{\text {th }}$ point as $15.79 \mathrm{~cm}$. and the minimum bouncing height has measured at $22^{\text {th }}$ point as $14.57 \mathrm{~cm}$ for third bouncing.

The sorted results according to the first, second and third bouncing height have been given below
1- A Type 3 Pro Table
2- C Type 5 Table with Metal Legs.
3- B Type 4 Table Wooden Legs.

The unique part of the study is the low cost ball dropping and measurement system. Thus the most convenient solution aimed at confirmation of product quality which is the biggest problem of industrial production is executed.

\section{REFERENCES}

Beyer, H. A., Uffenkamp, V. And Van Der Vlugt, G., 1995. Quality control in industry with digital Photogrammetry. Optical 3-D measurement techniques III pp: 29-38.

Brown, J. And Dold, J., 1995.—a system for digital industrial photogrammetry, V-stars. pp. 12-21.

Fraser, C.S. and Shortis, M.R., 1995. Metric exploitation of still video imagery. Photogrammetric Record, 15(85) : pp.107122. 
Fraser, C. S., 1997. Innovations in automation for vision metrology systems. Photogrammetric Record,

(15)90: pp.901-911.

Ganci, G. and Shortis, M.R., 1995a. Videometric as-built surveys during the manufacture of a furnace hopper. Proceedings, 3rd Symposium on Surveillance and Monitoring Surveys, Melbourne, Australia, pp. 59-69

Neale W. T. C., Fenton S., McFadden S. and Rose N. A.,2004 A Video Tracking Photogrammetry Technique To SurveyRoadways for Accident Reconstruction, Knott Laboratory.

Pettersen, A., 1992. Metrology Norway System - an on line industrial photogrammetry system. International Archives of Photogrammetry and Remote Sensing, 29(5): pp.43-49.

Samuhelová A, 2004, Using terrestrial photogrammetry for Documentation of sights, Aplikácia Pozemnej Fotogrametrie Pri Dokumentácii.

Schneider, C.-T., 1996. DPA-WIN-a PC based digital photogrammetric station for fast and flexible On-site measurement. International Archives of Photogrammetry and Remote Sensing, 31(B5):pp. 530-533.

Tan H., Bai X., Lin G.,2011, Surface Accuracy Measurement and Analysis of an Inflatable Antenna by Photogrammetry, Cross Strait Quad-Regional Radio Science and Wireless Technology Conference, July 26-30, Harbin, China, pp.11221124 